\title{
Law and the Public's Health
}

\section{STATE LAWS PERMITTING INTOXICATION EXCLUSIONS IN INSURANCE CONTRACTS: IMPLICATIONS FOR PUBLIC HEALTH POLICY AND PRACTICE}

\author{
Joel Teitelbaum, JD, LLM \\ Sara Rosenbaum, JD \\ ERIC Goplerud, PHD
}

This installment of Law and the Public's Health examines the problem of state laws that permit various types of insurers to exclude from coverage all costs related to "intoxication" injuries and considers the implications of these laws for public health policy and practice. Although laws permitting insurers to use intoxication exclusionary clauses have fallen out of favor with the National Association of Insurance Commissioners (NAIC), nearly all states and the District of Columbia continue to explicitly or implicitly permit licensed insurers to exclude coverage for diagnostic and treatment services for conditions related to the use of alcohol or drugs. ${ }^{1}$ Such exclusions not only have potentially significant consequences for health care quality and financing, but also may impede efforts to protect the public's health through efforts to encourage providers to promptly identify and begin treatment for acute intoxication and chronic substance use disorders. Indeed, laws permitting intoxication exclusions represent a fundamental disjunction between evidence-based medical care on the one hand and health financing on the other, since intoxication exclusions financially disincentivize precisely the type of medical response that has been identified as a benchmark of clinically appropriate medical care. ${ }^{2}$

\section{BACKGROUND AND OVERVIEW}

State laws permitting the use of intoxication exclusionary clauses in insurance contracts have their roots in the 1947 Uniform Accident and Sickness Policy Provision Law (the so-called UPPL), a non-binding model statute drafted by NAIC. By the mid-1950s, most states had adopted the model law in principle. Currently, 37 states and the District of Columbia expressly permit the exclusions, while another eight are silent on the matter (silence in insurance regulation is treated by courts as permitting the use of exclusions by insurers)..$^{1}$ In recent years, four states have repealed their permissive statutes in the case of certain forms of insurance ${ }^{1}$ (although the California legislature's repeal of the exclusion in a health insurance context was recently vetoed by Governor Schwarzenegger), while three states prohibit outright intoxication clauses in all forms of insurance (e.g., health, disability, property and casualty). (Notably, even if a state were to prohibit the use of an intoxicant exclusion in, say, health insurance contracts, its use may remain in other types of insurance products, such as workers compensation, accidental death and dismemberment, disability, auto, and property and casualty policies.)
Standing alone, state tolerance for intoxication exclusions in insurance contracts reflects a natural patchwork of state-level policy preferences. This variable approach to insurance law, however, raises complex issues in numerous contexts: the increasing financial burdens confronting the nation's hospital trauma centers, whose service areas may be regional; the legal screening and stabilization obligations of emergency departments and trauma centers under the Emergency Medical Treatment and Labor Act (still referred to as EMTALA, the acronym for the law's original title), which leave them vulnerable to coverage denials; the contradiction between the exclusion and the evolution of medical understanding regarding substance abuse disorders as treatable conditions; and the individual and public health benefits that flow from appropriate medical intervention at the point of trauma. Indeed, NAIC has not only repealed its initial policy in favor of intoxication exclusions, it recommended their outright prohibition. Yet intoxication exclusion statutes have remained on state code books in spite of the development of seemingly contradictory policy at both the state and federal levels. For example, these exclusionary statutes operate alongside other bodies of state law in the areas of highway safety, health care access, anti-discrimination, public health financing, and emergency medical care, which have evolved considerably since the 1950s. In the context of federal law, the exclusion-permissive state statutes appear to fundamentally contradict modern legal standards in areas such as emergency care obligations under EMTALA, public health care financing standards under Medicare, Medicaid, and the State Children's Health Insurance Program, federal anti-discrimination laws, and laws enacted to promote the public's health and improve health quality in Medicareparticipating institutions.

To understand the potential reach of this problem, the recent federal appeals court decision in Bishop v. National Health Insurance Co. ${ }^{3}$ - a rare public example of the application of an intoxication exclusion-is instructive.

\section{THE BISHOP DECISION}

Decided by the Second Circuit Court of Appeals in 2003, the Bishop case addressed the application of a UPPL-style intoxication exclusion to a Connecticut resident who experienced severe trauma involving intoxication. As such, Bishop began as a "garden variety" health insurance case focusing on the legality of coverage exclusions when they are neither prohibited by law nor so ambiguous that enforcement is barred (Connecticut is one of the states that is silent on the use of an intoxication exclusion).

In 1997, National Health Insurance Co. sold an insurance policy to Oliver Bishop III that covered both him and his son, Oliver Bishop IV. The policy excluded coverage for "any loss incurred while [the insured was] legally intoxicated." The policy further defined "intoxicated" as a level of blood alcohol content that is specified in the laws in the 
state where the loss or cause of loss occurred. Bishop IV had a major automobile accident while intoxicated (as defined by Connecticut's drunken driving law) and was treated at Yale-New Haven Hospital. Faced with more than a quartermillion dollars in medical bills, National Insurance refused coverage, prompting the Bishops to file a lawsuit.

The federal trial court refused to enforce the clause against the Bishops, citing its ambiguity under a legal principle known as contra proferentem, which requires that ambiguous provisions of written documents be construed most strongly against the individual or entity who selected the language (in Bishop, the insurance company). On appeal, however, the Second Circuit reversed this initial judgment and ruled in favor of National Insurance, upholding the intoxication exclusion as both legal under state insurance law and unambiguous in its terms.

As a practical matter, the financial and health care quality implications of Bishop are enormous. As a result of the decision, all coverage for treatment associated with Bishop IV's injuries incurred while intoxicated (presumably, both the short-term treatment and longer-term rehabilitation) would be excluded from the contract; Yale-New Haven Hospital and other providers would have to seek payment directly from the family. State law would determine the extent of the father's legal liability to pay for medical care; all liability might instead rest with the son. At the same time, Bishop aptly captures the broader conceptual problem of intoxication exclusions in insurance contracts and employersponsored benefit plans: the profound negative ramifications for health care professionals, their patients, and patients' families, as well as for the financial stability of the nation's trauma centers and state health and welfare budgets that potentially bear much of the short- and long-term financial burden created by the exclusions.

\section{IMPLICATIONS FOR PUBLIC HEALTH POLICY AND PRACTICE}

No comprehensive analysis exists of the extent to which providers try to prevent the triggering of intoxication exclusions through the avoidance of certain medical cases or of methods of treatment. Evidence does exist, however, that in markets in which an intoxication exclusion is in effect, health care institutions may be deterred from aggressive screening and intervention practices because of the risk of non-payment for the care they provide. ${ }^{4}$ Putting aside the ethical and quality-of-care considerations this predicament raises, it is worth pointing out that state laws permitting the exclusions may encourage hospitals to act in a manner contrary to their EMTALA obligations by attempting to unlawfully divert emergency cases that are believed to involve alcohol- or druginduced events. Put another way, states may, by implication, be encouraging substandard health care trauma practice.

Beyond even these troubling issues, however, states may through their acceptance of UPPL-style exclusions expose themselves and others to unwanted (and, from a policy perspective, perhaps unnecessary) financial liability. In essence, states that allow insurer autonomy to adopt the exclusions are placing themselves, insured persons throughout their state who must absorb bad debt, the federal government (through a multitude of health programs aimed at the longterm medical management of individuals with disabilities), and families of those injured in the position of being insurers of first resort in the face of intoxication-related injuries.

Yet even in the face of these implications, the extent to which intoxication exclusions are present and operational in various forms of insurance and health benefits coverage is not completely understood. Moreover, no comprehensive analyses exist of policy options for diminishing or eliminating barriers to treatment and health care financing that flow from the exclusions, or of the extent to which various federal and state laws may actually bar the use of such exclusionary clauses in one or more forms of coverage.

From a policy reform perspective, states could, for example, require insurers in the individual market to offer at least some coverage for intoxication injury (e.g., no denial of trauma coverage, or coverage subject to an upper limit), much in the way that most states now require at least some coverage for catastrophic costs related to mental illness. ${ }^{5}$ States also might establish risk pools through insurance surtaxes to support compensation for trauma services and follow-up care associated with intoxication. States might also mandate that insurers prove by clear and convincing evidence that intoxication was the proximate cause of an injury before denying coverage pursuant to a blanket intoxication exclusion. Federal policy options might include conditioning state participation in Medicaid on the adoption of one or more approved legislative approaches that avert the default of intoxication costs onto public funds.

Beyond policy reform, furthermore, is the issue of the extent to which existing federal laws may actually bar the use of intoxication exclusionary clauses in one or more forms of coverage. Although it is uncommon for federal law to preempt state insurance law (since under the McCarranFerguson Act states retain primary authority to regulate insurance), there are relevant examples. The best known is the Employee Retirement Income Security Act (ERISA), the preemptive force of which is so powerful that in its sphere of control it literally "occupies the field" and preempts all state laws that relate to employee health benefit plans even in the absence of a specific conflict. ${ }^{6}$ Other federal laws that address the design of insurance plans and may be potentially preemptive (either legally or in a broader policy sense) are Medicare, the Federal Employee Health Benefits Act, TriCare, and the non-discrimination provisions contained in the Health Insurance Portability and Accountability Act. In terms of remedial laws, the Americans with Disabilities Act (ADA) may have preemptive force over the application of the exclusion to the extent that an insurer's conduct can be understood as discrimination under the ADA.

At the heart of the state intoxication exclusion laws lies an important policy question: whether certain health care costs should be borne by society at large (through general revenues or dedicated taxes) or (at least in part) as a dimension of insurance contracts. Thirty years ago, the United States Supreme Court confronted a similarly seminal question in the case of Metropolitan Life Insurance Co. v. Massachusetts, ${ }^{5}$ in which the Court held that states could regulate insured ERISA plans to mandate mental health care coverage. While the Metropolitan Life decision is rather technical, 
it nonetheless reflects a deeper policy direction, namely, that the costs associated with care for mental illnesses and substance use disorders are legitimate insured costs, not merely costs to be borne by taxpayers. Preservation of what appears to be an outmoded intoxication exclusion across insurance products represents the same type of policy choice that insurers' routine exclusion of mental illness costs reflected a generation ago. Whether society can afford to retain this type of exclusionary and discriminatory approach to insurance coverage is an issue that continues to receive major policy attention at all levels of government.

The authors are with the Department of Health Policy, The George Washington University Medical Center, School of Public Health and Health Services, Washington, DC. Joel Teitelbaum is Associate Professor and Vice Chair, Department of Health Policy, and Managing Director of the School's Hirsh Health Law and Policy Program. Sara Rosenbaum is the Hirsh Professor of Health
Law and Policy, Chair of the Department of Health Policy, and Director of the Hirsh Health Law and Policy Program. Dr. Eric Goplerud is Research Professor and Director, Ensuring Solutions to Alcohol Problems, Department of Health Policy.

\section{REFERENCES}

1. National Institute on Alcohol Abuse and Alcoholism. Alcohol Policy Information System [cited 2004 Jul 12]. Available from: URL http://www.alcoholpolicy.niaaa.nih.gov/

2. McGlynn EA, Asch SM, Adams J, Keesey J, Hicks J, DeCristofaro A, et al. The quality of health care delivered to adults in the United States. N Engl J Med 2003;348:2635-45.

3. 344 F.3d 305 (2d Circuit 2003).

4. Zimmerman R. Why emergency rooms rarely test trauma patients for alcohol, drugs. Wall Street Journal $2003 \mathrm{Feb} 26 ;$ p. 6 .

5. Metropolitan Life Insurance Co. v. Massachusetts. 421 U.S. 724 (1985).

6. Rosenblatt R, Law S, Rosenbaum S. Law and the American health care system. Westbury (NY): Foundation Press; 1997. 